\title{
Borges Frente a la Poesía Gauchesca: Crítica y Creación
}

El interés que Jorge Luis Borges ha manifestado en temas metafísicos universales - el tiempo, la eternidad, el infinito, la identidad personaly su versación en otras literaturas han tendido a oscurecer lo que hay de hondamente argentino en su producción. Un estudio atento revela la sostenida presencia de lo nacional, como querencia y como preocupación, a lo largo de su obra. Aunque descuidado por la crítica, su firme arraigo en una concreta realidad histórica, geográfica, lingǘstica y literaria debe tomarse en cuenta para lograr una imagen equilibrada y total del escritor. ${ }^{1}$ Al estudiar a Borges en su doble papel de comentarista de la poesía gauchesca y feliz recreador de algunos de sus motivos, se llega a percibir uno de los rasgos olvidados de su perfil literatio.

Las circunstancias que lo impulsan a interesarse en lo gauchesco se aclaran al repasar su biografía y al evocar el contexto político-cultural de los años veinte. El joven Borges regresa a Buenos Aires en 1921, después de haber pasado en Europa siete años inmerso en otras culturas, asimilando literaturas extranjeras. El reencuentro con su ciudad natal despierta en él dormidas vivencias y lo sacude emocionalmente, como lo revelan - desde el mismo título- las poesías de su primer libro, Pervor de Buenos Aires (1923). Si bien durante un tiempo actúa como propagandista y portavoz del ultraísmo - la moda literaria que concedía importancia capital a la metáfora, y en cuya gestación había participado en España-, no tarda en gravitar paulatinamente hacia el criollismo.

Las tendencias ideológicas que predominan por esos años en la Atgentina contribuyen a explicar esta reorientación estética. Borges vuelve a su patria cuando está por terminar la primera presidencia de Hipólito Irigoyen (1916-22), que marca para el país el comienzo de un periodo en que el nacionalismo se convierte en politica oficial, con el entusiasta

1 He analizado la dimensión histórica de la obra de este autor y el efecto del cambio político sobre ella en "The final creole: Borges' view of Argentine history", TriQuarterly, No. 25 (Fall 1.972), 149-171. 
apoyo de la ciudadanía. Este rumbo, que continúa en buena medida bajo el presidente Marcelo T. de Alvear (1922-28) y retorna como bandera de lucha durante el desdichado regreso de Irigoyen al poder (1928-30), se manifiesta en una política internacional independiente, en un esfuerzo por detener la penettación económica extranjera y por asegurar el control estatal sobre la explotación de ciertos productos básicos y los transportes. Este nacionalismo no sólo refleja la influencia de ideologías europeas contemporáneas sino que también responde al impacto sociocultural causado por el aluvión inmigratorio que desde fines del siglo diecinueve había comenzado a inundar la Argentina y en particular su capital. En efecto, hacia 1914 vivían en Buenos Aires tantos argentinos como extranjeros, principalmente españoles e italianos. Como respuesta a esta invasión pacífica, los argentinos de antiguo arraigo y -curiosamente- los hijos de inmigrantes se unen en una entusiasta exaltación de lo típico del país. Surge el culto al gaucho y la pampa, elevados pronto a la categoría de símbolo y esencia de la auténtica nacionalidad. El payador (1916) de Leopoldo Lugones y la sección que Ricardo Rojas dedica a "Los gauchescos" en su Historia de la literatura argentina (1917-22) marcan la pauta de esta reacción ideológica en el campo literario.

Aunque separados de estos autores por divergencias estéticas y políticas, un núcleo de vanguardistas atgentinos se une al movimiento de exaltación de lo nativo. En la revista Martín Fierro (1924-27) convergen sus inquietudes, cuyo más sàzonado fruto es la novela Don Segundo Sombra (1926), en que Ricardo Güiraldes hermana artísticamente un tema criollo con las últimas técnicas literarias europeas. El criollismo del grupo martinfierrista, además de reflejar condiciones locales, está vinculado a un amplio movimiento que en el mundo occidental afecta a las artes y las letras. Reaccionando contra los excesos de una estética ultracivilizada y lúdica, varios pintores, poetas y escultores buscan en diversos paises un reencuentro con lo primitivo, lo telúrico, lo raigal. Formas hispánicas de esta corriente, a la que a veces se añaden reivindicaciones sociales, son el neocriollismo de Ramón López Velarde, la poesía afrocubana de Nicolás Guillén, las leyendas guatemaltecas de Miguel Angel Asturias, el gitanismo de Federico García Lorca y la nueva novela indigenista hispanoamericana que aflora por aquellos años.

Si bien Borges no perteneció al grupo martinfierrista, los libros que publica en la segunda mitad de la década del veinte revelan varias concomitancias con su ideario. A través de la poesía, el ensayo y la biografía se percibe su acuciosa búsqueda de lo argentino típico: Luna de enfrente (1925), Inquisiciones (1925), El tamaño de mi esperanza (1926), El idioma de los argentinos (1928), Cuaderm San Martin (1929), y 
Evaristo Carriego (1930). Los rasgos fundamentales de estas obras son, en lo temático, la poetización del arrabal y el compadrito porteño; en 10 idiomático, un intento de reproducir el habla de Buenos Aires; en lo ideológico, el rechazo de lo extranjero y la exaltación del coraje individual en varios personajes elegidos en la historia nacional y entre sus propios antepasados familiares. Años más tarde, en su poesía "Mil novecientos veintitantos", Borges recordaría aquella época y su amistad con Guiraldes: "Yo tramaba una humilde mitología de tapias y cuchillos / y Ricardo pensaba en sus reseros" (OP, 202).2

En esos años de fervor nacionalista, Borges repudia lo que considera una alteración del carácter auténtico del país provocada por lo foráneo. "Ya la República se nos extranjeriza, se nos pierde. Fracasa el criollo", declara en un ensayo que publica en 1925 bajo el significativo título de "Queja de todo criollo" (I, 138). Y "la culpa de que los alambres encarcelen la pampa, de que el gauchaje se haya quebrantado" la tienen a su parecer los remanidos conceptos de "argentinidad y progreso". Ante este peligro de desnaturalización se hace necesario formentar "un arte criollo" $(I, 136)$ : "Creo que deberían nuestros versos tener sabor de patria, como guitarra que sabe a soledades y a campo y a poniente detrás de un trebolar..." (I, 19).

\section{I}

Fiel a su nuevo credo estético, Borges comienza a publicar ensayos sobre escritores gauchescos y criollistas de ambas márgenes del Río de la Plata. Pero a diferencia de sus compañeros de la vanguardia argentina, su interés por el tema rebasa los límites de una moda pasajera. Disuelto el grupo martinfierrista y superado el estridente nacionalismo de los años mozos, continúa escribiendo estudios sobre las figuras destacadas de la literatura gauchesca, desde el iniciador Bartolomé Hidalgo hasta los continuadores neocriollistas, como Fernán Silva Valdés.

Sus trabajos de crítica, que con el tiempo llegan a la veintena, no son el resultado de una erudita investigación bibliográfica o lingüística, sino comentarios de lector atento en los que con frecuencia se iluminan aspectos que otros críticos más minuciosos no han percibido. Destaca así

2 Inserto en el texto la referencia al libro de Borges y a la página correspondiente, empleando las siguientes abreviaturas: $\mathrm{A}=E l$ Aleph $(1957), \mathrm{D}=$ Discusión (1957), EC = Evaristo Carriego (1955), ES = Elogio de la sombra (1969), $\mathrm{F}=$ Ficciones (1956), $\mathrm{H}=$ El bacedor (1960), $\mathrm{I}=$ Inquisiciones (1925), MF = El "Martin Fierra" (1953), OI = Otras inquisiciones (1960), $\mathrm{OP}=$ Obra poética 1923-1967 (1969), TE = El tamaño de mi ésperanza (1926). 
relaciones mutuas, señala peculiaridades y evalúa la creación de estos autores. Gracias a la ventajosa perspectiva que le asegura su conocimiento directo de varias literaturas, sus juicios de madurez carecen del apasionamiento o el provincialismo que aqueja a buena parte de la crítica que se ha ocupado del tema.

No sólo motivos generacionales impulsaron a Borges hacia el gaucho y hacia la literatura dedicada a recrear su figura y su mundo. Existen también factores personales. En el gaucho ha creído ver encarnada una de las cualidades que más admira: la valentía serena y desinteresada. "La dura vida - dice en un bello poema en prosa dedicado a los gauchos- les enseñó el culto del coraje" (ES, 100). Además hay una coincidencia geográfica. "La órbita del arte gauchesco - -señala- ha sido siempre ribereña del Plata" ( $($, 57). El territorio en que actúa el gaucho y florece la literatura gauchesca corresponde exactamente con la región favorita de Borges: la que tiene por centro a Buenos Aires y abarca en su radio las zonas circunvecinas de ambas márgenes del Río de la Plata. Esta es la tierra en que él mismo nació y en la que actuaron y mutieron casi todos sus antepasados.

El gaucho aparece durante el período colonial en las dos confusas e inestables fronteras cercanas a Buenos Aires. Hacia el norte y el este asoma en la región de conflicto con los portugueses; por el sur y el oeste, en las tierras de fricción con el indígena. Borges ve a los gauchos en tensión entre el indio y el europeo o el criollo: "Mestizos de la sangre del hombre blanco, lo tuvieron en poco, mestizos de la sangre del hombre rojo, fueton sus enemigos" (ES, 99). En otro lugar añade que el gaucho fue más un tipo social que étnico, un hombre típico que se desarrolla en una sociedad dedicada a la ganadería primitiva ${ }^{3}$ y que desaparece en la medida en que se impone la agricultura intensiva.

Borges formula un planteo coherente de la génesis, trayectoria y singularidad de la poesía gauchesca en las letras americanas. Señala que aunque ha habido vida pastoril semejante en otras regiones del continente, este tipo de literatura ha florecido sólo en las repúblicas rioplatenses. Pero el estilo vital de los gauchos no basta para explicar su aparición ni su popularidad en todos los niveles sociales de la Argentina y el Uruguay. Era necesaria, en primer lugar, la existencia de hombres de la ciudad que se compenetratan con él. De ello se encargaron las compartidas tareas rurales $y$, principalmente, los conflictos militares que convulsionaron esas regiones en la primera mitad del siglo diecinueve: "En la guerra de la independencia, en la guerra con el Brasil y en las

3. Jorge Luis Borges y Adolfo Bioy Casares (eds.), Poesía gauchesca (México, 1955), I, viii. 
guerras civiles, hombres de la ciudad convivieron con hombres de la campaña, se identificaron con ellos y pudieron concebir y ejeccutar, sin falsificación, la admirable poesía gauchesca" (MF, 11). Se da así la paradoja de que esta poesía no haya sido creada por gauchos, sino "por personas educadas, señores de Buenos Aires y Montevideo" (MF, 9) cuya imitación del dialecto gauchesco refleja la búsqueda de una autonomía cultural que acompañara a la independencia política lograda en 1810. "El 'gauchesco' es. . un escritor que se ve a sí mismo como rebelde contra la tradición y contra los literatos"."

Además, a medida que cambian las condiciones socioeconómicas de la región, los poetas van estilizando la figura del gaucho y acentuando los rasgos evocativos. "La literatura gauchesca - dice- fue siempre recordativa y nostálgica" ( $T E$, 88). "Jinete que se aleja y se pierde -añade en otro lugar-, con una sugestión de derrota, es. . en nuestras letras el gaucho" (EC, 127). Y es esa versión literaria del personaje, en la que se idealiza su rudeza primitiva y su espíritu de independencia, la que ha terminado por imponerse como más verdadera que la real.

La explicación que Borges hace de los orígenes de la poesía gauchesca contradice la tesis de Rojas y otros historiadores de la literatura argentina, que hacen derivar esta poesía del arte de los payadores o improvisadores profesionales de la campaña. Para Borges, en cambio, "hombres de la ciudad les fabricaron [a los gauchos] un dialecto y una poesía de metáforas rústicas" (ES, 100). A su juicio esa poesía, "que ha producido. . obras admirables, es un género artificial como cualquier otro" (D, 153).

En apoyo de su posición, Rojas había citado las coincidencias métricas y estróficas entre la poesía de los payadores y la de los "gauchescos", que permitirian establecer una relación de dependencia entre ésta y aquélla. Borges califica este planteo de "hábil errot" y arguye convincentemente que hay entre los dos tipos de poesía diferencias esenciales de motivación, vocabulario, temas y perspectiva. Los payadores, afirma, "no versificaron jamás en un lenguaje deliberadamente plebeyo y con imágenes derivadas de los trabajos manuales" (MF, 10). El pueblo, cuando versifica, "tiene la convicción de ejecutar algo importante, y rehúye instintivamente las voces populares y busca voces y giros altisonantes" (D, 154). La prueba de ello se encuentra en la segunda parte del Martin Fierro. Si bien todo el

4 Borges y Bioy Casares, Poesia gauchesca, I, ix. En un útil estudio titulado "La 'poesía gauchesca' como fenómeno literario"" (Revista Iberoame'ricana, XXVIII, 52 [julio-diciembre, 1961], 281-299) Aníbal Sánchez Reulet toma en cuenta las explicaciones de Borges sobre el origen de este peculiar género regional. Cree, sin embargo, que además de las circunstancias históricas y sociales apuntadas por Borges, hubo también factores ideológicos que desempeñaron un papel decisivo, tales como el influjo del romanticismo en el Río de la Plata y el surgimiento de una literatura nacionalista al servicio de la causa patriótica. 
poema está escrito en un lenguaje que quiere ser rústico, en los últimos cantos hay una" payada en que los dos contrincantes "olvidan el pobre mundo pastoril en que viven y abordan con inocencia o temeridad grandes temas abstractos: el tiempo, la eternidad, el canto de la noche, el canto del mar, el peso y la medida". Y agrega: "Es como si el mayor de los poetas gauchescos hubiera querido mostrarnos la diferencia que separa su trabajo deliberado de las irresponsables improvisaciones de los payadores" (MF, 10).

Borges distingue entre el ciclo de la poesía gauchesca - que se extiende por algo más de medio siglo y culmina con el Martín Fierro (1872, 1879) - y los escritores criollistas que contimúan sus lineamientos. Aunque ha dedicado varios ensayos a analizar aspectos de la producción de estos continuadores, particularmente a Eduardo Gutiérrez, Guillermo Entique Hudson, Ricardo Güiraldes, Pedro Leandro Ipuche y Fernán Silva Valdés, nos interesa aquí examinar sus estudios sobre los gauchescos. ${ }^{5}$ En ellos resalta su propósito de restablecer un equilibrio valorativo entre la obra de los poetas anteriores a Hernández y el Martin Fierro. Esto lo lleva, naturalmente, a revisar los juicios de Lugones y Rojas, con los que mantiene un sostenido contrapunto polémico.

La intención reivindicatoria resulta clara en las páginas que dedica a Bartolomé Hidalgo (1788-1822), a quien llama "el iniciador, el Adán" de la literatura gauchesca $(D, 13)$. Rechaza allí la denominación de "payador", que le aplica Rojas y la leyenda de autor iletrado que se le ha ido creando. Recuerda que antes de escribir los Diálogos patrióticos Hidalgo había compuesto sonetos y odas endecasílabas, formas poéticas poco compatibles con las de un presunto improvisador rural. Señala, además, que el poeta uruguayo se inició redactando melólogos, género mixto que consistía en una acción escénica, generalmente para un solo personaje, con un comentario musical que acompañaba la voz del actor o alternaba con ella, subrayando o anticipando el sentimiento que se expresaba. Al cultivar este extraño género, originario de España, Hidalgo habría concebido la idea germinal de la poesía gauchesca. Tal explicación, aunque sugestiva, no es imprescindible; como máximo, puede concedérsele un valor concomitante. Basta con admitir que Hidalgo conocía las actividades de los payadores y que adaptando su ruda forma poética, empleó

5 La trayectoria del pensamiento de Borges sobre la poesía gauchesca puede seguirse, a lo largo de cuatro décadas, en los siguientes trabajos: "Ascasubi" (I, 51-56), "El Fausto criollo" (TE, 11-17), "La pampa y el suburbio son dioses" (E, 18-24), "Las coplas acriolladas" (TE, 75-84), "El Coronel Ascasubi" (Sur, I, 1, 129-140), "El Martín Fierro" (Sur, I, 2, 134-145), El "Martín Fierro" (Buenos Aires, 1953), Poesía gauchesca, 2 vols. (México, 1955), "La poiesía gauchesca" (D, 11-38), "Martín Fierro" ( $\mathrm{H}, 35-36)$, The Spanish language in South America - a literary problem; El gaucbo Martín Fierro (London, 1964). 
la lengua vulgar para comunicar a un público iletrado temas políticos que le interesaban o afectaban.

Borges acierta al señalar que corresponde a Hidalgo el hallazgo de algunos motivos esenciales de la poesía gauchesca: "el diálogo entre paisanos, el ambiente sugerido por alusiones, las perplejidades del gaucho en la ciudad", y el tema de la amistad, que repiten sus continuadores. ${ }^{6}$ "Bartolomé Hidalgo - -dice Borges- descubre la entonación del gaucho; eso es mucho" (D, 14). Y en otro lugar abserva: "En mi corta experiencia de narrador he comprobado que saber cómo habla un personaje es saber quién es, que descubrir una entonación, una voz, una sintaxis peculiar, es haber descubierto un destino" (MF, 12). La paradójica gloria de Hidalgo radica, precisamente, en haber sido superado por sus imitadores en quienes, sin embargo, sigue percibiéndose su voz "inmortal, secreta y modesta" (MF, 12).

La producción de Hilario Ascasubi (1807-1875), que Borges venía leyendo desde los años de adolescencia en Ginebra, es objeto de uno de sus primeros estudios sobre un escritor gauchesco. Lo publica en 1925, entre los ensayos de Inquisiciones, y en él habla del "desaliñado placer" que le ha proporcionado la lectura del Santos Vega, obra "desdibujada y borrosa", que debe antologizarse para salvarla del olvido ( $I, 51,52$ ). Seis años después, en el primer número de la revista Sur, retoma polémicamente el tema para colocar a este autor en el sitio que a su juicio le corresponde dentro de los gauchescos. Aunque admite allí "la general inferioridad de Ascasubi" frente a Hernández, subraya su "frecuente superioridad parcial". ${ }^{7}$ Años más tarde precisa su opinión: "En Ascasubi hay rasgos más vívidos, más felicidad, más coraje, pero todo ello está fragmentario y secreto en tres tomos incidentales, de cuatrocientas páginas cada uno" (OI, 196). De ahí que termine por preferir trozos de las trovas que Ascasubi publicó bajo los seudónimos de Aniceto el Gallo y Paulino Lucero a la "casi interminable novela métrica Santos Vega" que "ha perjudicado la fama póstuma de su autor" ( $\mathrm{MF}, 15)$.

Contra la afirmación de Lugones, y contra lo que él mismo había sostenido en su primer artículo sobre este autor, Borges afirma en 1953 que Ascasubi no prefigura la obra de Hernández. A su juicio, la producción de aquél "es radicalmente distinta y busca otros fines". Y añade: "El Martin Fierro es triste; los versos de Ascasubi son felices y valerosos y tienen un carácter visual, del todo ajeno a la manera de Hernández" (MF, 13). Esa capacidad descriptiva y escénica de Ascasubi es la que permite presentar en forma mucho más vívida que Hernández las inva-

- Borges y Bioy Casares, Poesia gauchesca, I, ix.

7 "El Coronel Ascasubi", Str, I, 1, 130. 
siones de los indios en la frontera de Buenos Aires, un espectáculo que él nunca había observado. En suma, Borges cree que mientras Hidalgo interesa a los historiadores de la literatura, la obra de Ascasubi tiene valor estético en las letras rioplatenses. Pero a diferencia de Hidalgo, cuyo tono es el de paisanos decentes, Ascasubi tiene frecuentemente la entonación del orilleto criollo.

Los años han ido atenuando el entusiasmo fervoroso que Borges sentía en su juventud por el Fausto de Estanislao del Campo (1834-1880). En 1925 lo consideraba "la mejor poesía que ha dicho nuestra América" (TE, 13), y en otro lugar lo sitúa a la par del Quijote, como una de las dos obras que a su juicio merecen "una inmortalidad de renombre" (I, 6). Vínculos político-familiares refuerzan y explican en parte esta encendida admiración, que data de su niñez. Del Campo había sido tío de un abuelo de Borges, había militado junto a él en las contiendas civiles defendiendo la posición de Buenos Aires, y en el combate había dado muestras de desusada valentía. Además, Borges encuentra expresados en el Fausto criollo el gozo de vivir, la felicidad y la amistad sincera, cualidades que por esos años atraían poderosamente a este joven algo tímido y solitario.

En 1953, al compararlo con el Martin Fierro, admite que la indole gauchesca del Fansto es menos esencial que formal, y que a pesar de su vocabulario ostentosamente rural está lejos de la mentalidad del paisano. Sin embargo, defiende a Del Campo de la doble crítica de ignorancia y artificiosidad. "Los errores que se han advertido en el Fausto -afirma - son distracciones, debidas precisamente al desahogo de quien está tratando una materia que conoce muy bien y no se demora en la verificación de detalles" (MF, 17). En cuanto a la posibilidad de que un gaucho pueda comprender y narrar el argumento de una ópera cantada en otro idioma, recuerda que esta convención es parte de Ja broma general de la obra. Quienes critican esto, dice en otro lugar, "olvidan que todo arte es convencional; también lo es la payada biográfica de Martín Fierro" (D, 23). Lo perdurable, en fin, "es el espléndido espectáculo de la amistad que propone el Fousto" (MF, 17).

Para Borges, ni Hidalgo, ni Ascasubi, ni Del Campo fueron en realidad precursores de Hernández, salvo el recurso compartido de haber hecho hablar a gauchos en lengua campesina; en cambio cree que Antonio D. Lussich (1848-1928) sí lo fue. Este poeta uruguayo, cuya obła apenas se conoce en la Argentina, publicó en Buenos Aires a mediados de 1872 un largo poema gauchesco titulado Los tres gaucbos orientales en el que fos protagonistas narran sus aventuras y desengaños en una fracasada revolución contra el gobierno. Hay algo en el tono de las confidencias 
y quejas de estos gauchos que anticipa las protestas y lamentos de Fierro. Los pasajes paralelos de ambos poemas que Borges aduce demuestran que, en efecto, Hernández conoció la obra de Lussich mientras trabajaba en la primera parte de su Martín Fierro, publicada pocos meses después ese mismo año de 1872. Los diálogos gauchescos de Lussich serían así "un borrador ocasional, pero indiscutible, de la obra definitiva de Hernández" (MF, 23).

Ningún tema literario ha despertado en Borges reacciones tan equívocas o contradictorias como el Martín Fierro, poema culminante de la literatura gauchesca y título a la inmortalidad artística de José Hernández (1834-1886). Es cierto que a través de sus trabajos críticos puede seguirse un proceso general que, partiendo de una actitud reservada o negativa, va evolucionando hacia una postura más favorable; pero también lo es que nunca llega a expresar un juicio inequívocamente positivo acerca de esta obra. Así en un artículo juvenil dedicado a The Purple Land dice preferir esta novela de Guillermo Enrique Hudson -escrita en inglés pero "pensada" en criollo- al Martín Fierro, y critica la "palinodia desdichadísima" que Hernández inserta al final de su poema, al pedir para el gaucho casa, escuela, iglesia y derechos (TE, 32, 34). Hacia 1941 ve el contenido del libro de Hernández meramente como "la autobiografía de un cuchillero, falseada por bravatas y por quejumbres que casi profetizan el tango" (OI, 196). Sin embargo, al cerrat en 1953 su estudio sobre El Martín Fierro, escrito con el "objeto principal" de promover la lectura del poema $(M F, 8)$, afirma que la literatura argentina cuenta a lo menos con un libro, el de Hernández.

Estos altibajos valorativos y otros que podrían señalarse se comprenden cuando se los considera como reflejos de una polémica ideológica que, desde fines de la década del treinta, Borges ha venido librando con los ultranacionalistas argentinos, cuando se tiene presente su insobornable postura crítica -para la que no hay intocables patrióticos en la literatura- y cuando se recuerda el efecto de atracción y rechazo que la violencia primitiva ejerce sobre este autor. Se entiende así su sostenida réplica a muchos planteos de Lugones y Rojas, su interés por destacar el valor de los antecedentes gauchescos de Hernández, su afán -algo exagetado-- de desvincular la obra de Hidalgo de la de los payadores, su insistencia en señalar que la poesía gauchesca es un género tan artificial como cualquier otro, su resistencia a considerar el Martín Fierro como obra paradigmática para los escritores argentinos. Esto último es lo que subraya en una importante conferencia que puede fecharse en torno a 1943, época de apogeo del nacionalismo en el país: "Creo que el Martín Fierro es la obra más perdurable que hemos escrito los argentinos; y creo con la 
misma intensidad que no podemos suponer que el Martín Fierro es, conzo algunas veces se ha dicho, nuestra Biblia, nuestro libro canónico" (D, 152). Así, mientras por un lado señala los valores literarios del poema de Hernández, por otro defiende el derecho del escritor a la libertad artística.

Borges cree, como Lugones, que en el Martín Fierro se percibe el fenómeno de la creación inconsciente. Para Hernández y sus contempotáneos el poema era una obra de tesis, un alegato político-social en contra de la conscripción ilegal y en defensa del gancho. Sin embargo, el sentido perdurable del libro sobrepasa ese propósito original del autor: "Hernández escribió para denunciar injusticias locales y temporales, pero en su obra entraron el mal, el destino y la desventura, que son eternos" (MF, 30). Contra lo que opina Lugones, Borges sostiene que el Martin Fierro no es una epopeya en el sentido clásico del término; al contrario, los cantos que narran las experiencias del protagonista en el servicio fronterizo son justamente los más antimilitaristas de la obra al presentar con vividez los rigores inútiles, los abusos y las arbitrariedades que debe soportar Fierro en el ejército. "No sé -añade en una entrevista- hasta dónde puede ser épica la historia de un desertor, de un prófugo". ${ }^{8}$ Tampoco acepta que el Martin Fierro sea el libro nacional de los argentinos - lo que la Iluada, la Divina Comedia o el Quijote son para sus respectivos países-, pues no es posible condensar la compleja historia secular de la patria "en el caso individual de un cuchillero de mil ochocientos setenta" (MF, 70). En cuanto al tono, reacciona negativamente ante el sentimentalismo y la autocompasión que percibe en las efusiones de Fierro, y prefiere en cambio Ia dureza viril de los versos de Ascasubi.

Borges sostiene que la controversia que rodea al poema de Hernández se aclara en gran medida cuando se deslinda la virtud estética de la obra del valor ético del protagonista, y se admite que aquélla no depende de éste. "Yo creo - ha dicho en otro diálogo- que, estéticamente, el Midtín Fierro es un gran libro, pero que motalmente es una obra baja...; el héroe es un personaje bastante desagradable". ${ }^{10}$ Entre los aciertos de Hernández destaca dos que apuntalan la verosimilitud del personaje: el hacer sentir vivamente el paisaje de la pampa sin describirlo y el presentar los hechos de la vida de Fierro como si no los conociera en su totalidad. En trance de clasificar por su género al Martín Fierro, propone la curiosa tesis de que se trata de una novela en verso, escrita

8 César Fernández Moreno, "Harto de los laberintos", Mundo Narevo, XVIII (Diciembre 1967), 21.

9 Fernández Moreno, p. 18.

10 Nicolás Cócaro, "Borges el hombre, Borges el escritor", La Nación, Buenos Aires, 13 de setiembre de 1970, 4a. sec., p. 1 . 
precisamente durante el siglo novelístico por excelencia. El juicio de Borges sobre el poema y su protagonista queda resumido en el párrafo con que cierra su estudio de 1953:

El pobre Martín Fierro no está en las confusas muertes que obró ni en los excesos de protesta y bravata que entorpecen la crónica de sus desdichas. Está en la entonación y en la respiración de los versos; en la inocencia que rememora modestas y perdidas felicida. des y en el coraje que no ignora que el hombre ha nacido para sufrir. Asi, me parece, lo sentimos instintivamente los argentinos. Las vicisitudes de Fierto nos importan menos que la persona que las vivió .... Expresar un hombre que las futuras generaciones no querrán olvidar es uno de los fines del arte; José Hernández lo ha logrado con plenitud. (MF, 75, 76).

\section{II}

El interés de Borges en la poesía gauchesca, y particularmente en el poema de Hernández, rebasa el plano de la crítica y penetra en la creación. Dos narraciones que parten de episodios culminantes del Martín Fierro - obra capaz de soportar, a su juicio, "casi inagotables repeticiones, versiones, perversiones" (A, 53) - revelan su talento para remozar motivos dados, y lo insertan a modo de eslabón reciente en la centenaria tradición de cultivadores de lo gauchesco. Sin embargo, su nueva aproximación a este mundo literario está depurada del criollismo programático de los años veinte. ${ }^{11}$

La "Biografía de Tadeo Isidoro Cruz (1829-1874)", publicada en 1944, es una de las natraciones perfectas de Botges: concisa - poco más de cuatro páginas-, vívida, equilibrada, con elementos regionales, familiares y especulativos attísticamente integrados. El cuento propone una versión de la existencia de Cruz antetior a su aparición en el Martín Fierro. Utilizando un conocido tecurso narrativo que los cuentos policiales han explotado - -el de ir suministrando datos aislados que anticipan el desenlace-, Borges insinúa paulatinamente a lo largo de la historia la relación de lo que narra con el poema de Hernández; pero la identi-

11 En su conferencia ya citada sobre "El escritor argentino y la tradición" (D, 151-162), Borges define su nueva posición frente al tema del nacionalismo literario, proponiendo un arte argentino más allá de lo pintoresco o lo intencionadamente típico. 
dad del protagonista, sugerida en el título, sólo se revela por completo en las dos últimas palabras de la narración.

El primer párrafo, sobrio y denso, crea la atmósfera del cuento e ilustra el estilo que caracteriza la prosa narrativa de Borges entre 1940 y 1955 :

El seis de febrero de 1829 , los montoneros que, hostigados ya por Lavalle, marchaban desde el Sur para incorporarse a las divisiones de López, hicieron alto en una estancia cuyo nombre ignoraban, a tres o cuatro leguas del P'ergamino; hacia el alba, uno de los hombres tuvo una pesadilla tenaz: en la penumbra del galpón, el confuso grito despertó a la mujer que dormía con él. Nadie sabe lo que soñó, pues al otro día, a las cuatro, los montoneros fueron desbaratados por la caballería de Suárez y la persecución duró nueve leguas, hasta los pajonales ya lóbregos, y el hombre pereció en una zanja, partido el cráneo por un sable de las guerras del Perú y del Brasil. La mujer se Ilamaba Isidora Cruz; el hijo que turo recibió el nombre de Tadeo Isidoro. (A, 53).

Borges, dueño de su estilo, logra varios fines en este apretado pasaje inicial. Establece la verosimilitud del relato con un tono de cronista, mencionando personajes y sucesos históticos conocidos: montoneros, Lava1le, López. Inserta a su propia familia en el relato al mencionar a individuos que llevan los apellidos de sus antepasados: Suárez, Acevedo, Laprida. Sugiere el mundo del destino y las premoniciones mediante la pesadilla del gaucho que habría de morir al día siguiente. $Y$, a la vez, diseña el paisaje esencial rehuyendo las tentaciones del pintoresquismo regionalista que veinte años antes le habría dictado palabras como jagüel, gaucho, china o pingo. A Borges le bastan ahora unos pocos términos precisos de uso general: estancia, galpón, leguas, pajonales, zanja. Hasta la contracción presente en la frase "a tres o cuatro leguas del Pergamino" le permite aludir tanto a un lugar geográfico como a una época anterior a la actual (hoy se omite el artículo).

El siguiente párrafo contiene varias claves que se suman al apellido del personaje central y van destinadas al lector atento. La primera alude a una supuesta y conocida fuente documental. "Mi propósito no es repetir su historia - dice refiriéndose al protagonista--: De los días y noches que la componen, sólo me interesa una noche... La aventura consta en un libro insigne" ( $A, 53)$. La segunda se insinúa poco después: "Cuando, en 1874, Cruz murió de la viruela negra, no había visto jamás una montaña ni un pico de gas ni un molino" (A, 54). Luego imagina 
una visita del personaje central a la ciudad de Buenos Aires, arreando una tropa de ganado. Sus compañeros entran en ella para divertirse, pero él prefiere quedarse en una fonda cercana a los corrales: "Pasó ahí muchos días, taciturno, durmiendo en la tierra, mateando, levantándose al alba y recogiéndose a la oración. Comprendió (más allá de las palabras y aún del entendimiento) que nada tenía que ver con él la ciudad". Esta desconfianza del gaucho hacia la ciudad hostil que finalmente lo eliminará -objeto de un sugestivo ensayo de Borges-12 viene aquí a subrayar el primitivismo raigal de Cruz y anticipa su futuro y súbito cambio de bando obedeciendo a una secreta ley interior. Al continuar el relato, Borges adjudica a Cruz detalles de un incidente que en el poema aparece protagonizado por Fierro: el encuentro con la partida policial. Cruz ha cometido un homicidio, provocado por su rival, y huye:

Prófugo, hubo de guarecerse en un fachinal; noches déspués, el grito de un chajá le advirtió que lo había cercado la policía. Probó el cuchillo en una mata; para que no le estorbaran en la de a pie, se quitó las espuelas. Prefirió pelear a entregarse. (A, 54)

Quienes han leído el Martin Fierro sienten aquí la resonancia de esta escena, cuyo vocabulario Borges toma prestado del poema de Hernández:

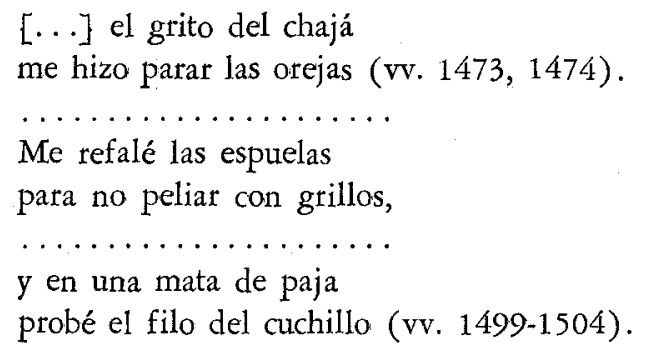

Cruz cae malherido en manos de las autoridades y sirve su condena en un fortín de la frontera, otro episodio de la vida de Fierro. Entretanto, Borges ha ido entrelazando en el relato los apellidos de sus propios antepasados. El padre de Cruz muere con el cráneo partido "por un sable de las guerras del Perú y del Brasil" cuando la montonera de que forma parte es desbaratada "por la caballería de Suárez" (A, 53). Cruz va a Buenos Aires "con una tropa del establecimiento de Francisco Xavier Acevedo" (A, 54), y en la frontera lucha valerosamente contra los indios "al mando del Sargento Mayor Eusebio Laprida" (A, 55).

\footnotetext{
12 "Historia de jinetes" (EC, 121-129).
} 
Antes de referir el encuentro decisivo, Borges se detiene para subrayar lo que le atrae en la historia y, en cierto modo, para justificar su manipulación de la conocida anécdota. De la vida del protagonista no le interesa su deserción a tierra de indígenas ni su trágica muerte. Lo que concita su interés es el incidente que marca un nuevo rumbo a la existencia de Cruz, porque le permite explayarse en un tema favorito: el hallazgo del destino personal. ${ }^{13}$

En aquel tiempo Cruz debió de considerarse feliz, aunque profundamente no lo era. (Lo esperaba, secreta en el porvenir, una lúcida noche fundamental: la noche en que por fin vio su propia cara, la noche en que por fin escuchó su nombre. Bien entendida, esa noche agota su historia; mejor dicho, un instante de esa noche, un acto de esa noche, porque los actos son nuestro símbolo.) Cualquier destino, por largo y complicado que sea, consta en realidad de un solo momento: el momento en que el hombre sabe para siempre quién es. $(A, 55)$

La narración -en que Borges ha integrado su mundo geográfico, familiar y metafísico- culmina dramáticamente cuando Cruz, al frente de la partida policial, se acerca al criminal acorralado cuya crecida melena y barba gris "parecían comerle la cara" (A, 56). Para los distraídos, el autor acota: "Un motivo notorio me veda referir la pelea". Súbitamente Cruz

comprendió que las jinetas y el uniforme ya le estorbaban. Cormprendió su intimo destino de lobo, no de perro gregario; comprendió que el otro era él. Amanecía en la desaforada llanura; Cruz arrojó por tierra el quepis, gritó que no iba a consentir el delito de que se matara a un valiente y se puso a pelear contra los soldados, junto al desertor Martín Fierro. (A, 57)

La gestación de "El fin", cuento aparecido en octubre de 1953, está vinculada directamente con los estudios que sobre la literatura gauchesca venía haciendo Borges por entonces. Estas reflexiones cristalizan ese mismo año en su ensayo $E l$ "Martín Fierro" y dos años después en Poesía gauchesca, una edición de poemas de Hidalgo, Ascasubi, Del Campo, Lussich, Hernández y Lynch, que prepara con Adolfo Bioy Casares y publica en México el Fondo de Cultura Económica. Al referirse en el primer libro

$13 \mathrm{El}$ año anterior Borges había expresado vívidamente esta idea en su "Poema conjetural" (OP, 142-143). 
a la payada final del poema de Hernández, que considera uno de los episodios más significativos de la obra, dice Borges: "El desafío del moreno incluye otro, cuya gravitación creciente sentimos, y prepara o prefigura otra cosa, que luego no sucede o que sucede más allá del poema" (MF, 61). Y después añade: "Podemos imaginar una pelea más allá del poema, en la que el moreno venga la muerte de su hermano" (MF, 65). "El fin", como insinúa su título, es precisamente la culminación de la violen. cia contenida que Borges percibe en el duelo verbal entre Fierro y el moreno.

Desde la payada han pasado siete años, durante los cuales el negro ha aguardado pacientemente el regreso del matador de su hermano. Un día el forastero vuelve a la pulpería para saldar la deuda. Borges presenta las alternativas de la acción desde la perspectiva del dueño de la pulpería, un vasco acriollado a quien una hemiplejía ha dejado inútil en un catre. El relato adquiere así los caracteres de un libreto cinematográfico adecuado a la técnica de cámara anclada:

La llanura, bajo el último sol, era casi abstracta, como vista en un sueño. Un punto se agitó en el horizonte y creció hasta ser un jinete, que venía, o parecía venir, a la casa. Recabarren vio el chambergo, el largo poncho oscuro, el caballo moro, pero no la cara del hombre, que, por fin, sujetó el galope y vino acercándose al trotecito. A unas doscientas varas dobló. Recabarren no lo vio más, pero lo oyó chistar, apearse, atar el caballo al palenque y entrar con paso firme en la pulpería. ( $F, 178)$

El diálogo entre los protagonistas es breve y tenso, a pesar del aparente desgano. Conforme a su interpretación del personaje, según la cual Martín Fierro dista de ser un modelo de conducta, Borges lo insinúa algo cínico. Aunque Fierro presiente que están por trabarse en un duelo a muerte, responde a una observación del moreno refiriéndose de este modo a sus hijos: "Les di buenos consejos..., que nunca están de más y no cuestan nada. Les dije, entre otras cosas, que el hombre no debe derramar la sangre del hombre" (F, 179). En el comentario del interlocutor palpitan una esperanza y una amenaza: "Hizo bien. Así no se parecerán a nosotros" (F, 180). Por último, los dos salen a la llanura infinita como para cumplir un rito primitivo. Mientras prepara el desenlace, Borges comunica con destreża las sensaciones que despierta el anochecer en la pampa: "Hay una hora de la tarde en que la llanura está por decir algo; nunca lo dice o tal vez lo dice infinitamente y no lo entendemos, o lo entendemos pero es intraducible como una música..." (F, 180). Desde 
su catre, el pulpero ve el fin. Martín Fierro alcanza a marcar al moreno en la cara, pero éste lo hiere con dos puñaladas profundas:

Fierro no se levantó. Inmóvil, el negro parecía vigilar su agonía laboriosa. Limpió el facón ensangrentado en el pasto y volvió a las casas con lentitud, sin mirar para atrás. Cumplida su tarea de justiciero, ahora era nadie. Mejor dicho era el otro: no tenía destino sobre la tierra y había matado a un hombre. (F, 180)

Hay en estas sobrias palabras finales del autor más que un juego con el concepto de la identidad intercambiable. Borges dice que el moreno es "el otro" porque ahora él es el victimario, el hombre marcado, en una cadena interminable de homicidios y venganzas.

Cuatro años más tarde, cuando la dictadura que oprimía a la Argentina ha sido derribada mediante una sangrienta revolución militar, Borges vuelve a referirse al duelo del poema en una prosa titulada "Martín Fierro" (1957). Ahonda allí la idea sugerida en las últimas líneas de "El fin" y presenta su concepción de la historia nacional ligándola al poema de Hernández:

En una pieza de hotel, hacia mil ochocientos sesenta y tantos, un hombre soñó una pelea. Un gaucho alza a un moreno con el cuchillo, lo tira como un saco de huesos, lo ve agonizar y morir, se agacha para limpiar el acero, desata su caballo y monta despacio, para que no piensen que huye. Esto que fue una vez vuelve a ser, infinitamente: los visibles ejércitos se fueron y queda un pobre duelo a cuchillo. $(H, 36)$

El Martin Fierro, viene a decirnos Borges, es el libro argentino por excelencia como querían Lugones y Rojas, pero por motivos diferentes de los que éstos proponían. El acierto de Hernández consistió en captar artísticamente en su poema los dos hemisferios del temperamento argentino: la amistad viril y la violencia fratricida. ${ }^{14}$

\section{Andrews University}

Humberto M. Rasi

14 Al revisar las pruebas de imprenta de este trabajo, llega a mis manos el estudio de Pedro Luis Barcia, "Proyección de Martín Fierro en dos ficciones de Borges" (en José Hernández: estudios reunidos en commemoración del centenario de "El gaucho Martín Fierro", 1872-1972 [La Plata, Argentinh, Universidad Nacional, 1973], 209-232). Barcia analiza también la "Biografía de Tadeo Isidoro Cruz" y "El fin", destacando con acierto el sentido metafísico de ambas narraciones. 